Bul1. Mater. Sci., Vol. 2, Number 1, January 1980, pp. 67-70. (C) Printed in India.

\title{
Phase transformation studies on pure and doped strontium carbonate*
}

\author{
C RAMA MOHAN RAO and P N MEHROTRA \\ Department of Chemistry, University of Roorkee, Roorkee 247672
}

MS received 21 November 1979 ; revised 3 January 1980

\begin{abstract}
The orthorhombic-hexagonal transformation of strontium carbonate is a reversible reconstructive transformation. Cationic impurities like $\mathrm{K}^{+}, \mathrm{Ca}^{2+}, \mathrm{Ba}^{2-}$, $\mathrm{Cd}^{2+}, \mathrm{Y}^{3+}, \mathrm{La}^{3+}, \mathrm{Nd}^{3+}, \mathrm{Sm}^{3+}, \mathrm{Gd}^{3+}, \mathrm{Dy}^{3+}, \mathrm{Ho}^{3+}, \mathrm{Bi}^{3+}, \mathrm{Zr}^{4+}$ doped in pure strontium carbonate affect the kinetics and energetics of the transformation.
\end{abstract}

Keywords. Phase transformations; strontium carbonate; orthorhombic-hexagonal transformation.

\section{Introduction}

The orthorhombic-hexagonal transformation of strontium carbonate is a rever, sible reconstructive transformation involving a change in the primary coordinationthe transformation is therefore expected to be sluggish and associated with high activation energy (Rao and Rao 1967). Although the orthorhomibic-hexagonal transformation of pure strontium carbonate has been examined by several workers (Lander 1951; Gruver 1950; Baker 1962; Smykatz-Kloss 1964) there is limited information in the literature on the effect of impurities on the enthalpy, kinetjes and energetics of the transformation. We have investigated this aspect. Such a study is of particular importance, as the incorporation of foreign ions can give rise to controlled electronic disorders, i.e., valency change or controlled atomic disorder, i.e. cation vacancy, etc.; these changes markedly effect phase transformation of solids (Subba Rao et al 1968; Rao and Mehrotra 1978). In the present investigation, the kinetics and energetics of orthorhombic-hexagonal transformation of strontium carbonate with known amounts of different impurity cations have been studied. The values for enthalpy of transformation $(\triangle H)$ and energy of activation $\left(E_{a}\right)$, for pure and different impurity doped samples of strontium carbonate have been evaluated from differential thermal analysis (DTA) data.

\section{Experimental}

Samples of pure and doped strontium carbonate were prepared by hydrolysis of the trichloroacetate salts (Rao and Yoganarasimhan 1965). The procedure yielded

\footnotetext{
* Paper presented at the Annual Convention of Chemists held at Andhra University, Waltair, December 1978.
} 
pure samples and avoided unintentional incorporation of impurities. For the preparation of doped samples, known amounts of impurity cations $\left(\mathrm{K}^{+}, \mathrm{Ca}^{2+}\right.$, $\mathrm{Ba}^{2+}, \mathrm{Cd}^{2+}, \mathrm{Y}^{3+}, \mathrm{La}^{3+}, \mathrm{Nd}^{3+}, \mathrm{Sm}^{3+}, \mathrm{Gd}^{3+}, \mathrm{Dy}^{3+}, \mathrm{Ho}^{3+}, \mathrm{Bi}^{3+}, \mathrm{Zr}^{4+}$ ) were taken in the form of carbonates or oxides along with the sample of pure strontium carbonate before reacting with trichloroacetic acid. The impurity percentage indicated in different cases are those which were added at the time of preparation. The impurity cations were chosen on the basis of their ionic size. All the chemicals used were of analytical grade.

Fisher differential thermo-analyser Model 260, fitted with an automatic voltage stabiliser and a recorder, has been used for the DTA studies. The particle size of the sample was within 100 to 200 mesh (BSS). Quartz crucibles were used as sample and reference holders with the sample amount of about $100 \mathrm{mg}$. The curves were recorded at a heating rate of $10 \% \mathrm{~min}$. Cooling curves were recorded at uncontrolled cooling rate. The temperature was measured on a calibrated platinum-platinum rhodium thermocouple with reference junction at $0^{\circ} \mathrm{C}$. Calcined $a-$ alumina was used as the reference material. The experiments were carried out under static air atmosphere. The activation energy was calculated following the method of Borchardt and Daniels (1957). $\triangle H$ values were computed by comparing the area of transformation peak for the doped samples with the orthorhombic (II)-hexagonal (I) transformation peak of pure potassium sulphate (Majumdar and Roy 1965; Rao and Rao 1966).

\section{Results and discussion}

The $\triangle H$ values estimated from peak areas may have an uncertainty of $\pm 5 \%$. The activation energy values obtained by employing the procedure of Borchardt and Daniels may have large uncertain ties ( $\pm 10 \%$, but the comparison of values in related systems would be valid (Rao and Rao 1966; Rao and Mehrotra 1979). The temperature at the starting point of the DTA peak for the forward transformation, forward transformation peak temperature and backward transformation peak temperature, $\triangle H$ value for the forward transformation $\left(\Delta H_{f}\right), \Delta H$ value for the backward transformation $\left(\triangle H_{q}\right)$ and $E_{\mathrm{a}}$ value of the forward transformation $\left(E_{\mathrm{a}}\right)$ for the pure and doped samples of strontium carbonate are listed in table 1.

It is evident from table 1 that the incorporation of impurities affects peak temperature forward transformation, forward transformation peak temperature, backward transformation, $\triangle H$ and $E_{u}$ values. The $E_{a}$ value for the various doped samples range from 840 to $2860 \mathrm{~kJ} / \mathrm{mole}$ as compared to $2540 \mathrm{~kJ} / \mathrm{mol}$ for the pure strontium carbonate. The variation in the values of $\Delta H_{f}$ and $\Delta H_{r}$ is also fairly large ranging from 13.4 to $24.3 \mathrm{~kJ} / \mathrm{mole}$ and 13.0 to $21.8 \mathrm{~kJ} /$ mole respectively as compared to 20.9 and $18.8 \mathrm{~kJ} /$ mole for the pure strontium carbonate when potassium sulphate is taken as standard. It may be pointed out that the values reported here may not be the absolute values but are sufficient to indicate the trend of variation in similar systems.

As shown in table 1, the thermal hysteresis in the transformation of pure strontium carbonate is $\sim 65^{\circ}$. Hysteresis is a necessary consequence of the coexistence of two phases (Ubblehode 1957) and the magnitude of hysteresis is determined by the relative volumes of the high temperature and low temperature phases (Rao 
Table 1. Impurity effects on the phase transformation of strontium carbonate.

\begin{tabular}{|c|c|c|c|c|c|c|c|}
\hline \multirow{2}{*}{ Impurity+ $(\%)$} & \multicolumn{3}{|c|}{ Transformation temperature } & \multirow{2}{*}{$\underset{\mathrm{kJ} / \mathrm{mole}}{\triangle H_{f}}$} & \multirow{2}{*}{$\underset{\mathrm{kJ} / \mathrm{mole}}{\triangle H_{\mathrm{r}}}$} & \multirow{2}{*}{$\underset{\mathrm{kJ} / \text { mole }}{E_{e}}$} & \multirow{2}{*}{$\begin{array}{c}\text { Ionic } \\
\operatorname{radii}(\mathrm{nm})\end{array}$} \\
\hline & $\begin{array}{c}\text { Forward } \\
{ }^{\circ} \mathrm{C}\end{array}$ & $\begin{array}{l}\text { Forward } \\
\text { peak }{ }^{\circ} \mathrm{C}\end{array}$ & $\begin{array}{l}\text { Backward } \\
\text { peak }{ }^{\circ} \mathrm{C}\end{array}$ & & & & \\
\hline None & 909 & 930 & 865 & $20 \cdot 9$ & $18 \cdot 8$ & 2540 & $0 \cdot 113$ \\
\hline $\mathrm{K}(1 \cdot 0)$ & 921 & 939 & 880 & $23 \cdot 0$ & $20 \cdot 5$ & 2860 & \\
\hline$K(5 \cdot 0)$ & 918 & 935 & 876 & $21 \cdot 8$ & $20 \cdot 1$ & 2,600 & 0.133 \\
\hline$K(10 \cdot 0)$ & 913 & 932 & 871 & $21 \cdot 3$ & $19 \cdot 7$ & 2380 & \\
\hline $\mathrm{Ca}(1 \cdot 0)$ & 903 & 925 & 858 & $18 \cdot 4$ & $16 \cdot 3$ & 2200 & \\
\hline $\mathrm{Ca}(5 \cdot 0)$ & 892 & 918 & 846 & $15 \cdot 5$ & $15 \cdot 1$ & 1720 & 0.099 \\
\hline $\mathrm{Ca}(10 \cdot 0)$ & 867 & 907 & 823 & $13 \cdot 4$ & $13 \cdot 0$ & 840 & \\
\hline $\mathrm{Ba}(1 \cdot 0)$ & 909 & 927 & 860 & $18 \cdot 8$ & $17 \cdot 6$ & 2340 & \\
\hline $\mathrm{Ba}(5 \cdot 0)$ & 901 & 919 & 848 & $16 \cdot 8$ & $16 \cdot 3$ & 2080 & $0 \cdot 135$ \\
\hline $\mathrm{Ba}(10 \cdot 0)$ & 889 & 906 & 837 & $15 \cdot 1$ & $14 \cdot 6$ & 1600 & \\
\hline $\mathrm{Cd}(1 \cdot 0)$ & 909 & 930 & 864 & $20 \cdot 1$ & $17 \cdot 6$ & 2210 & \\
\hline $\mathrm{Cd}(5 \cdot 0)$ & 905 & 924 & 859 & $18 \cdot 4$ & $16 \cdot 7$ & 1900 & 0.097 \\
\hline $\mathrm{Cd}(10 \cdot 0)$ & 898 & 920 & 853 & $16 \cdot 7$ & $16 \cdot 3$ & 1730 & \\
\hline$Y(1 \cdot 0)$ & 908 & 928 & 865 & $21 \cdot 3$ & $18 \cdot 8$ & 2510 & \\
\hline$Y(5 \cdot 0)$ & 912 & 934 & 869 & $22 \cdot 6$ & $19 \cdot 7$ & 2660 & $0 \cdot 093$ \\
\hline$Y(10 \cdot 0)$ & 917 & 940 & 875 & $23 \cdot 4$ & $20 \cdot 9$ & 2850 & \\
\hline $\mathrm{La}(5 \cdot 0)$ & 919 & 943 & 876 & $24 \cdot 3$ & $21 \cdot 8$ & 2820 & $0 \cdot 115$ \\
\hline $\mathrm{Nd}(5 \cdot 0)$ & 916 & 938 & 874 & $23 \cdot 9$ & $20 \cdot 9$ & 2730 & $0 \cdot 108$ \\
\hline $\operatorname{Sm}(5 \cdot 0)$ & 913 & 936 & 873 & $22 \cdot 6$ & $20 \cdot 5$ & 2640 & $0 \cdot 104$ \\
\hline Gd (5.0) & 912 & 933 & 870 & $21 \cdot 8$ & $19 \cdot 3$ & 2570 & $0 \cdot 102$ \\
\hline Dy $(5 \cdot 0)$ & 912 & 931 & 865 & $21 \cdot 8$ & $18 \cdot 8$ & 2560 & 0.099 \\
\hline Ho $(5 \cdot 0)$ & 910 & 929 & 862 & $20 \cdot 5$ & $18 \cdot 0$ & 2480 & 0.097 \\
\hline $\operatorname{li}(5 \cdot 0)$ & 906 & 924 & 861 & $20 \cdot 1$ & $17 \cdot 6$ & 2230 & $0 \cdot 108$ \\
\hline $\operatorname{Zr}(5 \cdot 0)$ & 914 & 935 & 876 & $2.2 \cdot 2$ & $21 \cdot 3$ & 2750 & 0.080 \\
\hline
\end{tabular}

+ Impurity concentrations are in at. $\%$

and Rao 1966). The increased $\left(\sim 72^{\circ} \mathrm{C}\right)$ and the decreased $\left(\sim 59^{\circ} \mathrm{C}\right)$ hysteresis, occurring by the addition of 5 at. $\% \mathrm{Ca}^{2+}$ and $\mathrm{K}^{+}$, is likely to be due to the variation in $\Delta V$ caused by the presence of smaller and bigger cations respectively. Unfortunately, no crystallographic data are available on the low and high temperature forms of strontium carbonate with these impurities.

In the case of $\mathrm{K}^{+}$doped samples the $E_{a}$ and $\Delta H$ values increase for 1 at.\% impurity compared to that for pure strontium carbonate. On further increase in impurity content, both $E_{a}$ and $\Delta H$ values decrease regularly but still the values are higher than that for pure strontium carbonate. The forward and backward transformation temperatures follow the trend of $\Delta H$ values. With the increase in $\mathrm{Ca}^{2+}$ and $\mathrm{Ba}^{2+}$ impurity from 1 to 10 at.\% both $E_{a}$ and $\triangle H$ values decrease regularly. The transformation temperatures follow the trend of $\triangle H$ and $E_{a}$ values, in both the cases. A similar trend is observed in the case of $\mathrm{Cd}^{2+}$ doped samples. On increasing $\mathrm{Y}^{3+}$ impurity content from 1 to 10 at.\% both $E_{a}$ and $\triangle H$ values increase regularly. The transformation temperatures follow the trend of $\Delta H$ and $E_{a}$ values respectively. 
In the case of lanthanide-doped samples, $E_{a}$ and $\triangle H$ values decrease regularly from lanthanum to holmium as the ionic radii decrease (for the same at.\% impurity, i.e. $5 \%$ ).

A perusal of the data given in table 1 for the doped samples in general shows that as the $E_{a}$ values increase the starting point of the peak also shifts to a higher temperature and with the increase in $\Delta H$ values the transformation temperatures increase.

The variation of the forward and backward transformation temperatures and $E_{a}$ of the transformation with impurities is understandable (Rao and Rao 1967; Sharp 1972), but no reasoning can be put forward for the variation in the $\triangle H$ values with impurities. It seems likely that for $\mathrm{Ca}^{2+}$ ion impurity doped samples the lower $\triangle H$ values may be due to the fact that the orthorhombic-hexagonal transformation in this case occurs over wider temperature range causing broad and shallow DTA peaks. Accordingly, the $\triangle H$ values are low when the transformation temperature values are low.

The present findings reveal that if the oxidation state of the impurity cations is the same, but the ionic radij are different, the trends in the variation of $E_{\mathrm{a}}$ and $\triangle H$ values are similar, although there is a contrast in their behaviour when the absolute values of $E_{a}$ and $\triangle H$ are considered. It is also observed that $\mathrm{K}^{+}$and $\mathrm{Y}^{3+}$ impurities affect the transformation characteristics in a different manner; this may partly be due to the effect of cation and anion vacancies produced by +1 and +3 ions but these effects are difficult to assess from the present investigation. In the case of lanthanide doped samples, forward and backward transformation peak temperature, $\triangle H$ and $E_{a}$ values increase with the size of the impurity cation (for the same percentage of the impurity).

\section{Acknowledgement}

Financial assistance from the University Grants Commission, New Delhi, is gratefully acknowledged.

\section{References}

Baker E H 1962 J. Chem. Soc. p. 2525

Borchardt H J and Daniels F $1957 \mathrm{~J}$. Am. Chem. Soc. 7941

Gruver R M $1950 \mathrm{~J}$. Am. Ceram. Soc. 3396

Lander J 1951 J. Am. Chem. Soc. 735794

Majumdar A J and Roy R 1965 J. Phys. Chem. 691684

Rao C N R and Rao K J 1967 in Progress in solid state chemistry ed. H Reiss (New York: Pergamon Press) 431

Rao C R M and Mehrotra P N 1978 Can. J. Chem. 5632

Rao C R M and Mehrotra P N 1979 Thermochim. Acta 29180

Rao K J and Rao C N R 1966 J. Mater. Sci. 1238

Rao M S and Yoganarasimhan S R 1965 Am. Mineral. 501489

Sharp J H 1972 in Differential thermal analysis ed. R C Mackenzic (New York : Academic Press) 266

Smykatz-Kloss W 1964 Beitr. Miner. Petrogr. 9481

Subba Rao G V, Natarajan M and Rao C N R 1968 J. Am. Ceram. Soc. 51179

Ubblehode A R 1957 Rev. Chem. Soc. 11246 